\title{
A Mineralogical and Geochemical Analysis of Bed I in Olduvai Gorge, Tanzania
}

David M. Davis1, M. Sanam Chaudhary1, Alexandra M. Simpson1, Daniel M. Deocampo1, Nathan M. Rabideaux1, Gail Ashley2, Kevin Garrett2

1 Georgia State University, Dept. of Geosciences; 2Rutgers University, Dept. of Earth and Planetary Sciences

Olduvai Gorge is located in northern Tanzania $\left(3^{\circ} \mathrm{S}, 35.35^{\circ} \mathrm{E}\right)$ on the Serengeti Plain and on the margin of the East Africa Rift System. Seventy-nine sediment samples were collected during the 2015 field season from a 6-meter high section of lacustrine sediment ( 1.9-1.86 Ma). Samples were collected at $\sim 15 \mathrm{~cm}$ intervals from $50 \mathrm{~cm}$ to $580 \mathrm{~cm}$. The purpose of these analyses are to determine the chemistry of clay minerals and whether, or not, authigenic clays can be used as paleoenvironmental proxies. Bulk minerology was obtained by XRD analyses of random-oriented powder. Samples were analyzed for 15 minutes from 10 to 65 degrees $2 \theta$. An abundance of $\mathrm{K}$ feldspars were found and a few samples contained zeolites (phillipsite). Calcite is common, whereas dolomite is rare. XRD analyses of oriented clays were conducted on additional Bed I sediments, located 300 meters to the east. The samples were analyzed air-dried and ethylene glycol solvated from 3 to 45 degrees $2 \theta$ for 15 minutes in order to identify the major clay mineral phases. Previous work has shown that the major clay phases are authigenic illite, smectite and illite/smectite. Preliminary results from this study are consistent with these findings. Samples were also analyzed from 59 to 63 degrees $2 \theta$ for 30 minutes. The 060 peak positions varied from $1.510 \AA$ to $1.522 \AA$. This likely corresponds to variations in octahedral $\mathrm{Mg}$ from 1.5 to 2.5 atoms per half formula unit. This variation in $\mathrm{Mg}$ suggests fluctuation in salinity of paleo Lake Olduvai over the $\sim 35$ kyr period represented by the $\sim 5 \mathrm{~m}$ thick lake section. To conclude, preliminary results do suggest that clay chemistry and authigenic clay minerals can be used as paleoenvironmental proxies. 